\title{
ANALISIS KUALITAS KEUANGAN BANK DAERAH LAMONGAN MELALUI SISTEM PENGENDALIAN INTERNAL (Study pada Bank Daerah Lamongan)
}

\author{
Kusuma Wijaya \\ Prodi Akuntansi, Fakultas Ekonomi, Universitas Islam Lamongan \\ $\mathrm{Jl}$. Veteran No.53A Lamongan \\ Telp. ( 0322 ) 324706, Faks. ( 0322 ) 324706 \\ Email :jpim@unisla.ac.id
}

\begin{abstract}
ABSTRAK
This study aims to test empirically: Influence of Human Resources Competence, Internal Control System and Human Resources Competencee through Internal Control System to quality financial report of Bank of Lamongan. This research was conducted at Bank Daerah Lamongan, by using sample of 50 respondents. Data collection method used purposive saampling, while the data analysis technique used is Partial Least Squares (PLS) version 3.2.1.m3, hypothesis testing is done by using outer and iner model in valid data measurement, realibel and feasibel model in determination of dependent variable. The results showed, (1) Human Resource Competence Influential Non-Significant to Quality of PD Bank Regional Report of Lamongan. The higher the Human Resources Competence owned by PD Bank of Lamongan, the Quality of Finance produced by PD Bank Lamongan tend to be better. (2) Internal Control System (SPI) influential Non-Significant to the Quality of Financial Report PD Regional Bank Lamongan. The higher the SPI is implemented, the quality of financial statements produced by PD Bank Lamongan tend to be better. (3) Human Resource Competene Influence Significant to Qulity of Financial Report of Pd Bank of Lamongan Region through Internal Control System (SPI). The higher competence of PD Bank of Lamongan Region through the improvement of SPI application, has an impact on the improvement of Quality of Financial Report of PD Bank of Lamongan Region.
\end{abstract}

Keyword : Financial Quality of Lamongan Regional Bank, Internal Control System, and Human Resource Competence.

\section{PENDAHULUAN}

Laporan keuangan adalah suatu cerminan untuk dapat mengetahui apakah suatu kegiatan pemerintahan telah berjalan dengan baik, maka dari itu perbankan diharuskan untuk dapat menghasilkan laporan keuangan yang berkualitas, sehingga dari publikasi laporan keuangan tersebut dapat berguna bagi pihak yang berkepentingan dan menjadi dasar pengambilan keputusan.

Menurut Susilo bank merupakan suatu lembaga keuangan yaitu suatu badan usaha yang berfungsi sebagai perantara keuangan dari dua pihak, yakni pihak yang kekurangan dana dan membutuhkan dana. Bank sebagai lembaga perantara keuangan antara pihak yang kelebiahan dana dan pihak yang membutuhkan dana.

Persaingan antara bank besar maupun kecil yang semakin menjadikan bank untuk berusaha bertahan dan berkembang, pada dasarnya semua bank baik yang bergerak dibidang jasa perbankan memiliki tujuan yang sama dalam menjalankan usahanya yaitu mendapatkan keuntungan dan ikut serta 
dalam meningkatkan ekonomi masyarakat Indonesia.

Karyawan sebagai sumber daya manusia dari suatu perbankan perlu dikelola secara profesional agar terwujud keseimbangan atara kebutuhan pegawai dengan tuntutan dan kemampuan organisasi perbankan, keseimbangan tersebut merupakan kunci utama perbankan agar dapat berkembang secara produktif dan wajar. Berikut ini adalah sebuah tabel 1 Prosentase Laba (Rugi) bersih PD Bank Daerah Lamongan periode tahun 2012 sampai 2017 yang menunjukkan tingkat fluktuasi Laba selama 5 periode terakhir, dengan melihat tingkat fluktuasi tersebut peneliti dapat menemukan fenomena yang terjadi di Bank daerah Lamongan.

\section{Tabel 1}

\section{Prosentase Laba (Rugi) bersih PD Bank Daerah Lamongan}

\begin{tabular}{|c|c|c|}
\hline Tahun & $\begin{array}{c}\text { Laba(Rugi) } \\
\text { Bersih }\end{array}$ & Prosentase \\
\hline 2012 & 3.999 .675 & $12,8 \%$ \\
\hline 2013 & 4.585 .755 & $12,9 \%$ \\
\hline 2014 & 5.245 .555 & $13,2 \%$ \\
\hline 2015 & 6.044 .655 & $13,9 \%$ \\
\hline 2016 & 7.022 .423 & $14,3 \%$ \\
\hline 2017 & 8.188 .056 & \\
\hline
\end{tabular}

Sumber : Data diolah oleh peneliti

Berdasarkan Tabel 1 diatas menunjukkan tingkat fluktuasi Laba (Rugi) bersih dari periode tahun 20122017 mengalami kenaikan. Tahun 2012 ke tahun 2013 mengalami fluktuasi sebesar 12,8\%. Tahun 2013 ke tahun 2014 mengalami fluktuasi sebesar 12,9\%. Tahun 2014 ke 2015 mengalami fluktuasi sebesar $13,2 \%$. Tahun $20 \mathrm{ke}$ tahun 2016 mengalami fluktuasi sebesar 13,9\%. Tahun 2016 ke tahun 2017 mengalami fluktasi sebesar $14,3 \%$.

Tingkat fluktuasi Laba (Rugi) Bersih PD Bank Daerah Lamongan menunjukkan bahwa masih sangat minim. Lemahnya penerapan Sistem
Pengendalian Internal dan masih kurangnya Kompetensi Sumber Daya Manusia (SDM) yang masih belum optimal diduga berpengaruh terhadap kualitas keuangan sebagai faktor penyebab tidak tercapainya target yang telah direncanakan oleh PD Bank Daerah Lamongan.

Kompetensi SDM merupakan faktor terpenting dalam menciptakan laporan keuangan yang berkualitas karena yang menerapkan SPI adalah manusia (Indriasih, 2014). Kompetensi SDM terdiri dari 3 komponen, antara lain : (a)Pengetahuan, (b) Keahlian, dan (c) Perilaku.

Pengendalian internal dibangun dari lima komponen, sebagai berikut: (a)Lingkungan pengendalian; (b) Penilaian risiko; (c) Aktivitas pengendalian; (d) Informasi dan komunikasi; serta (e) Pemantauan. (PP Nomor 60 tahun 2008; Arens, 2014:345).

Laporan keuangan yang berkualitas menurut Peraturan Pemerintah Nomor 71 Tahun 2010 adalah laporan keuangan yang memiliki karakteristik relevan, andal, dapat dibandingkan serta dapat dipahami.

Berdasarkan uraian diatas dari fenomena dan temuan persentase laba dari tiap tahun.Peneliti mengambil judul "Analisis kualitas keuangan Bank Daerah Lamongan melalui sistem pengendalian internal (Study pada Bank Daerah Lamongan)".

\section{Perumusan Masalah}

Berdasarkan uraian latar belakang masalah di atas, maka pertanyaan penelitian dari penelitian ini adalah sebagai berikut:

1. Apakah Kompetensi SDM berpengaruh terhadap Kualitas Keuangan pada Bank Daerah Lamongan?

2. Apakah Sistem Pengendalian Internal berpengaruh terhadap Kualitas Keuangan 
pada Bank Daerah Lamongan?

3. Apakah Kompetensi SDM melalui Sistem Pengendalian Internal berpengaruh terhadap Kualitas Keuangan pada Bank Daerah Lamongan?

\section{Tujuan Penelitian}

Adapun tujuan penelitian ini adalah

1. Untuk menguji Kompetensi SDM berpengaruh terhadap Kualitas Keuangan pada Bank Daerah Lamongan.

2. Untuk membuktikan Sistem Pengendalian Internal berpengaruh terhadap Kualitas Keuangan pada Bank Daerah Lamongan.

3. Untuk menganalisis Kompetensi SDM melalui Sistem Pengendalian Internal berpengaruh terhadap Kualitas Keuangan pada Bank Daerah Lamongan.

\section{TELAAH LITERATUR}

Menurut Teguh Puspandoyo (2014), meneliti tentang Analisis Hubungan Antara Enterprise Resource Planning Dengan Efektivitas Pengendalian Internal Pada Sektor Perbankan. Penulis mencoba untuk menganalisis mengenai faktor-faktor kesuksesan implementasi ERP dihubungkan dengan faktor yang dapat meningkatkan efektivitas pengendalian internal. Hasil penelitian ini ERP berpengaruh signifikan terhadap pengendalian internal.

Mei Sari Simatupang (2017), melakukan penelitian tentang Pengaruh Sistem Pengendalian Intern Pemerintah, Sistem Akuntansi Keuangan Daerah Dan Kompetensi Sumber Daya Manusia Terhadap Efektivitas Pengelolaan Keuangan Daerah (Studi Pada Satuan Kerja Perangkat Daerah Kota Padangsidimpuan). Tujuan penelitian ini adalah bagaimana SPIP, Sistem Akuntansi Keuangan, dan kompetensi
SDM berpengaruh terhadap efektivitas pengelolaan keuangan daerah. Hasil dari penelitian ini adalah 1) Sistem pengendalian intern pemerintah (SPIP) berpengaruh terhadap efektivitas pengelolaan keuangan daerah. 2) Sistem akuntansi keuangan daerah berpengaruh terhadap efektivitas pengelolaan keuangan daerah. 3) Kompetensi sumber daya manusia berpengaruh terhadap efektivitas pengelolaan keuangan daerah.

\section{HIPOTESIS PENELITIAN}

1. Kompetensi SDM berpengaruh terhadap Kualitas Keuangan pada Bank Daerah Lamongan?

2. Sistem Pengendalian Internal berpengaruh terhadap Kualitas Keuangan pada Bank Daerah Lamongan?

3. Kompetensi SDM melalui Sisitem Pengendalian Internal berpengaruh terhadap Kualitas Keuangan pada Bank Daerah Lamongan?

\section{METODE PENELITIAN}

Penelitian ini dilakukan melalui pendekatan kuantitatif, yaitu pengaruh Kompetensi SDM (X1) secara parsial terhadap Kualitas Keuangan (Y), pengaruh Sistem Pengendalian Internal (X2) secara parsial terhadap Kualitas Keuangan (Y) dan pengaruh Kompetensi SDM (X1) melalui Sistem Pengendalian Internal (X2) secara parsial terhadap Kualitas Keuangan (Y). Objek penelitian ini adalah semua karyawan di lingkungan Kantor Bank Daerah Lamongan . Penelitian ini memperoleh data dari dua sumber yaitu adalah data primer dalam penelitian ini didapatkan melalui wawancara dan jawaban kuesioner dari responden serta data sekunder yaitu sumber data yang terdapat pada buku-buku, dan jurnal terdahulu yang ada hubungannya 
Tabel

Kuesioner Penelitian

Bagian A : Kualitas Laporan Keuangan Bank Daerah Lamongan

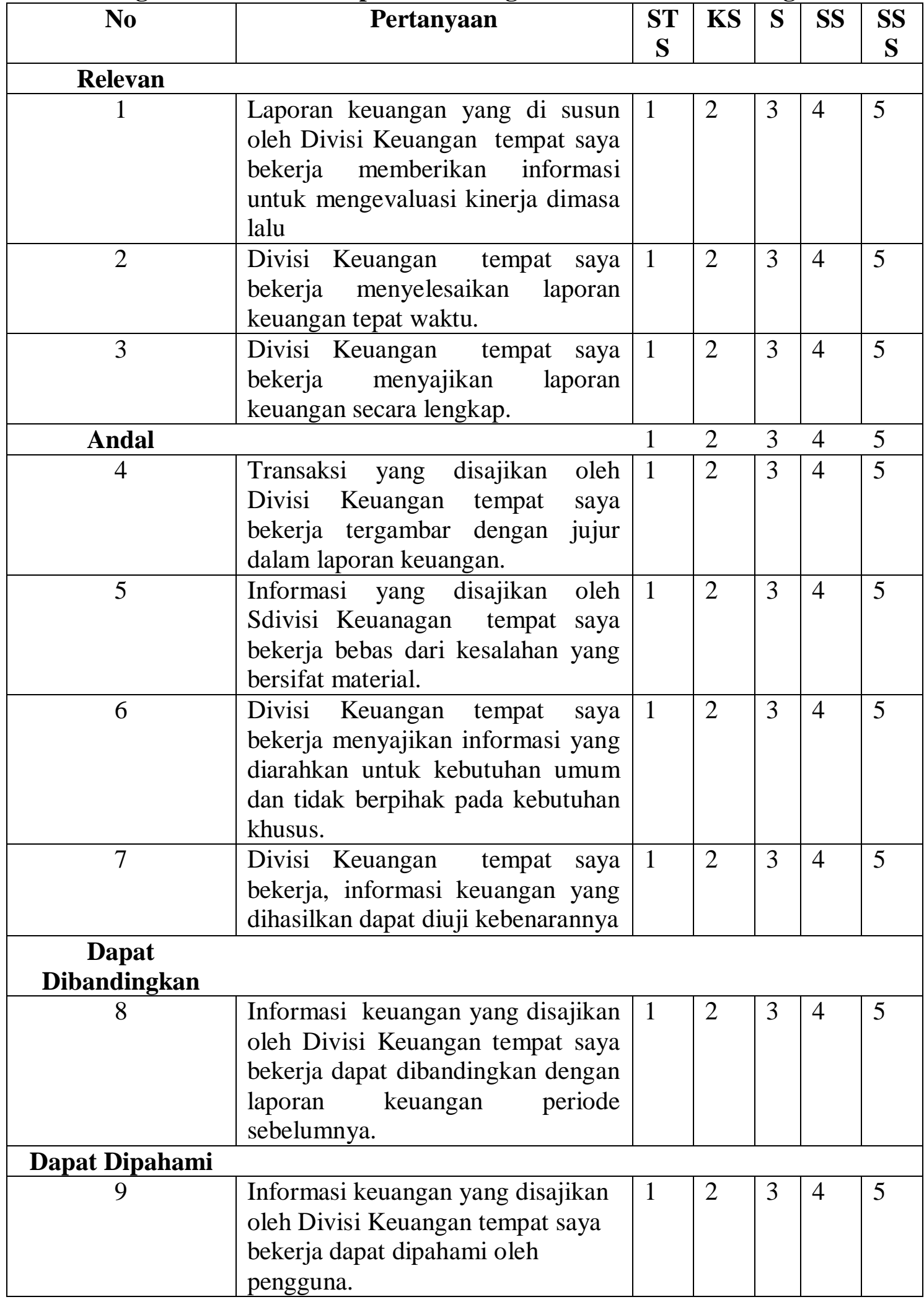


Sumber dari : PP No 71 Tahun 2010), Irwan (2011), Sudiarianti (2015)

Bagian B : Kompetensi Sumber Daya Manusia

\begin{tabular}{|c|c|c|c|c|c|c|}
\hline No & Pertanyaan & $\begin{array}{l}\text { ST } \\
\text { S }\end{array}$ & $\mathbf{K S}$ & $\mathbf{S}$ & SS & $\begin{array}{l}\text { SS } \\
\text { S }\end{array}$ \\
\hline \multicolumn{7}{|c|}{ Pengetahuan } \\
\hline 1 & $\begin{array}{l}\text { Menjalankan tugas pokok sesuai } \\
\text { dengan fungsi }\end{array}$ & 1 & 2 & 3 & 4 & 5 \\
\hline 2 & $\begin{array}{l}\text { Mengerti pengetahuan tentang } \\
\text { siklus akuntansi }\end{array}$ & 1 & 2 & 3 & 4 & 5 \\
\hline 3 & $\begin{array}{l}\text { Memahami pengetahuan tentang } \\
\text { peraturan yang telah ditetapkan }\end{array}$ & 1 & 2 & 3 & 4 & 5 \\
\hline \multicolumn{7}{|c|}{ Keahlian } \\
\hline 4 & $\begin{array}{l}\text { Kemampuan dalam menyusun } \\
\text { laporan keuangan }\end{array}$ & 1 & 2 & 3 & 4 & 5 \\
\hline 5 & $\begin{array}{l}\text { Telah mendapatkan pendidikan } \\
\text { dan pelatihan } \\
\text { Keuangan }\end{array}$ & 1 & 2 & 3 & 4 & 5 \\
\hline \multicolumn{7}{|c|}{ Perilaku } \\
\hline 7 & $\begin{array}{l}\text { Mengedepankan etika dalam } \\
\text { bekerja }\end{array}$ & 1 & 2 & 3 & 4 & 5 \\
\hline 8 & $\begin{array}{l}\text { Menolak terhadap intervensi yang } \\
\text { dapat menimbulkan pelanggaran }\end{array}$ & 1 & 2 & 3 & 4 & 5 \\
\hline
\end{tabular}

Sumber dari : PP No 71 Tahun 2010), Irwan (2011), Sudiarianti (2015)

Bagian C : Sistem Pengendalian Internal Bank Daerah Lamongan

\begin{tabular}{|c|l|l|l|l|l|l|l|}
\hline No & \multicolumn{1}{|c|}{ Pertanyaan } & $\begin{array}{c}\text { ST } \\
\text { S }\end{array}$ & KS & S & SS & $\begin{array}{c}\text { SS } \\
\text { S }\end{array}$ \\
\hline Lingkungan Pengendalian & $\begin{array}{l}\text { Penegakan nilai integritas } \\
\text { dan etika }\end{array}$ & 1 & 2 & 3 & 4 & 5 \\
\hline 1 & $\begin{array}{l}\text { Komitmen terhadap } \\
\text { Kompetensi pegawai }\end{array}$ & 1 & 2 & 3 & 4 & 5 \\
\hline 2 & $\begin{array}{l}\text { Ditempat saya bekerja } \\
\text { telah } \\
\text { penentuan batas dan } \\
\text { penentuan toleransi resiko } \\
\text { salah saji }\end{array}$ & 1 & 2 & 3 & 4 & 5 \\
\hline 3 & $\begin{array}{l}\text { Ditempat saya bekerja } \\
\text { telah } \\
\text { pengendalian intern dan } \\
\text { manajemen terhadap }\end{array}$ & 1 & 2 & 3 & 4 & 5 \\
\hline 4 & & & & & \\
\hline
\end{tabular}




\begin{tabular}{|c|c|c|c|c|c|c|}
\hline & resiko salah saji. & & & & & \\
\hline \multicolumn{7}{|c|}{ Kegiatan Pengendalian } \\
\hline 5 & $\begin{array}{lcr}\text { Setiap } & \text { transaksi dan } \\
\text { aktivitas ditempat saya } \\
\text { bekerja telah didukung } \\
\text { dengan otorisasi dari pihak } \\
\text { yang berwenang. }\end{array}$ & 1 & 2 & 3 & 4 & 5 \\
\hline 6 & $\begin{array}{l}\text { Ditempat saya bekerja } \\
\text { telah menerapkan } \\
\text { pemisahan tugas yang } \\
\text { memadai }\end{array}$ & 1 & 2 & 3 & 4 & 5 \\
\hline \multicolumn{7}{|c|}{$\begin{array}{c}\text { Informasi dan } \\
\text { Komunikasi }\end{array}$} \\
\hline 7 & $\begin{array}{l}\text { Ditempat saya bekerja } \\
\text { telah menerapkan sistem } \\
\text { informasi untuk } \\
\text { melaksanakan tanggung } \\
\text { jawab. }\end{array}$ & 1 & 2 & 3 & 4 & 5 \\
\hline 8 & $\begin{array}{l}\text { Ditempat saya bekerja } \\
\text { telah melaksanakan sistem } \\
\text { akuntansi yang } \\
\text { memungkinkan audit. }\end{array}$ & 1 & 2 & 3 & 4 & 5 \\
\hline \multicolumn{7}{|c|}{ Pemantauan } \\
\hline 9 & $\begin{array}{l}\text { Prosedur tindak lanjut dari } \\
\text { hasil temuan }\end{array}$ & 1 & 2 & 3 & 4 & 5 \\
\hline 10 & $\begin{array}{l}\text { Temuan dievaluasi, } \\
\text { ditanggapi dan dilaksankan }\end{array}$ & 1 & 2 & 3 & 4 & 5 \\
\hline
\end{tabular}

Sumber dari : PP No 71 Tahun 2010), Irwan (2011), Sudiarianti (2015) 
Kemudian terkait unit populasi dipilih Divisi-divisi yang ada di Bank Daerah Lamongan tersebut, karena para responden tersebut dianggap kompeten dan dapat memberikan persepsi yang objektif dan mengetahui masalah yang berkaitan dengan penelitian yaitu mengenai Kualitas Keuangan melalui sistem pengendalian internal. Teknik pengambilan sampling yang digunakan yaitu random sampling artinya sampel dipilih sebagian dari keseluruhan populasi. Dalam hal ini jumlah sampel diambil sebanyak 50 responden dengan 5 ekslembar kuesioner. Menurut Sugiyono, sampel adalah sebagian atau wakil dari subjek yang akan diteliti. Tehnik penentuan sampel dalam penelitian ini dilakukan dengan menggunakan teknik purposive sampling, yaitu teknik pengambilan sampel berdasarkan kriteria tertentu atau dengan pertimbangan (judgement) tertentu (Sugiyono, 2016:67). Skala pengukuran dalam penelitian ini yaitu skala Likert. Dengan ketentuan yaitu skor 5 bagi jawaban Sangat Setuju Sekali, skor 4 Sangat Setuju untuk jawaban, skor 3 bagi jawaban Setuju, skor 2 untuk jawaban Kurang Setuju dan skor 1 bagi jawaban Sangat Tidak Setuju. Teknik analisis dalam menguji hipotesis penelitian ini yaitu Smart PLS (Partial Least Square).

\section{HASIL PENELITIAN}

\section{Karakteristik Responden}

Dari kuesioner yang diharapkan memperoleh 70 responden yang berasal dari Pegawai Bank Daerah Lamongan, hanya 50 responden yang mengirimkan balasan kuesioner. 50 responden meliputi berbagai divisi yang ada dalam Bank Daerah Lamongan tersebut.
Tabel 3.1.

Responden Bank Daerah Lamongan

\begin{tabular}{|c|c|c|}
\hline Keterangan & Jumlah & Prosentase \\
\hline \multirow{7}{*}{$\begin{array}{l}\text { Divisi SPI } \\
\text { Divisi } \\
\text { Akuntansi } \\
\text { Pelaporan } \\
\text { Keuangan } \\
\text { Divisi SDM } \\
\text { Bagian IT } \\
\text { Total } \\
\text { Responden }\end{array}$} & 12 & 24 \\
\hline & 11 & 22 \\
\hline & 8 & 16 \\
\hline & & \\
\hline & 14 & 28 \\
\hline & 5 & 10 \\
\hline & 50 & 100,00 \\
\hline \multicolumn{3}{|l|}{$\begin{array}{l}\text { Jenis } \\
\text { Kelamin }\end{array}$} \\
\hline Pria & 35 & 70 \\
\hline Wanita & 15 & 30 \\
\hline $\begin{array}{l}\text { Total } \\
\text { Responden }\end{array}$ & 50 & 100,00 \\
\hline \multicolumn{3}{|l|}{$\begin{array}{l}\text { Tingkat } \\
\text { Pendidikan }\end{array}$} \\
\hline SMA/SMK & 18 & 36 \\
\hline S-1 & 21 & 42 \\
\hline \multirow{2}{*}{$\begin{array}{l}\text { S-2 } \\
\text { Total } \\
\text { Responden }\end{array}$} & 5 & 10 \\
\hline & 50 & 100,00 \\
\hline
\end{tabular}

Sumber : Data diolah oleh peneliti

Secara umum tingkatan usia atau umur seseorang dapat menunjukkan tingkat pendewasaan atau kematangan

\begin{tabular}{|c|c|c|}
\hline Umur & Frekuensi & Persentase \\
\hline $\begin{array}{c}19-30 \\
\text { tahun }\end{array}$ & 25 & 49,02 \\
\hline $\begin{array}{c}31-42 \\
\text { tahun }\end{array}$ & 14 & 29,41 \\
\hline $\begin{array}{c}43-54 \\
\text { tahun }\end{array}$ & 11 & 21,57 \\
\hline Total & $\mathbf{5 0}$ & $\mathbf{1 0 0 . 0}$ \\
\hline
\end{tabular}

dalam memecahkan suatu masalah yang sedang dihadapi, dibawah ini pembagian responden berdasarkan kelompok usia yang disajikan : 
Tabel 3.2

Responden berdasarkan Umur

Sumber : Data diolah peneliti

Lama waktu kerja responden terhitung dari tahun pertama waktu kerja sampai pada saat dilaksanakannya penelitian ini. Lamanya waktu kerja responden dalam penelitian ini terbagi menjadi empat kategori sebagai berikut :

\section{Tabel 3.3}

Responden berdasarkan lama waktu kerja

\begin{tabular}{|c|c|c|}
\hline $\begin{array}{c}\text { Lama } \\
\text { Waktu } \\
\text { Kerja }\end{array}$ & Frekuensi & Persentase \\
\hline 0-4 tahun & 20 & 41.18 \\
\hline 5-8 tahun & 8 & 15.68 \\
\hline 9-12 tahun & 12 & 23.53 \\
\hline$>12$ tahun & 10 & 19.61 \\
\hline
\end{tabular}

Sumber : Data diolah peneliti

Tabel 4.2

Prosentase indikator Kompetensi SDM

\begin{tabular}{|l|c|}
\hline \multicolumn{1}{|c|}{ Indikator } & $\mathbf{1}$ \\
\hline Pengetahuan & 69,2 \\
\hline Keahlian & 21 \\
\hline Perilaku & 26 \\
\hline Prosentase (\%) Rata-rata & $\mathbf{3 8 . 7}$ \\
\hline $\begin{array}{l}\text { Sumber : Data diolah peneliti } \\
\text { Berdasarkan tabel 4.2 diatas dapat }\end{array}$
\end{tabular}
disimpulkan bahwa jawaban responden cenderung berada pada skala 2 yakni sebanyak $42 \%$ responden menyatakan bahwa indikator dari Kompetensi SDM di Bank Daerah Lamongan masih belum mencapai harapan yang diinginkan Pemerintah Kabupaten Lamongan, oleh karena itu pegawai Bank Daerah Lamongan sering diikutkan diklat pelatihan penyusunan keuangan supaya dapat meningkatkan pelaporan kualitas keuangan Bank daerah Lamongan.
Tabel 5.2

Prosentase indikator Sistem Pengendalian Internal

\begin{tabular}{|l|c|c|c|c|c|l|}
\hline \multicolumn{1}{|c|}{ Indikator } & $\mathbf{1}$ & $\mathbf{2}$ & $\mathbf{3}$ & $\mathbf{4}$ & $\mathbf{5}$ & $\begin{array}{c}\text { Respo } \\
\text { nden }\end{array}$ \\
\hline $\begin{array}{l}\text { Lingkungan } \\
\text { Pengendalian }\end{array}$ & 26 & 39 & 29 & 6 & 0 & 50 \\
\hline $\begin{array}{l}\text { Penilaian } \\
\text { Risiko }\end{array}$ & 30 & 29 & 35 & 6 & 0 & 50 \\
\hline $\begin{array}{l}\text { Kegiatan } \\
\text { Pengendalian }\end{array}$ & 29 & 40 & 27 & 4 & 0 & 50 \\
\hline $\begin{array}{l}\text { Informasi dan } \\
\text { Komunikasi }\end{array}$ & 33 & 29 & 34 & 4 & 0 & 50 \\
\hline Pemantauan & 28 & 33 & 32 & 7 & 0 & 50 \\
\hline $\begin{array}{l}\text { Prosentase } \\
\text { (\%) Rata-rata }\end{array}$ & $\mathbf{2 9 , 2}$ & $\mathbf{3 4}$ & $\mathbf{3 1 , 4}$ & $\mathbf{5 . 4}$ & $\mathbf{0 . 0}$ & $\mathbf{1 0 0}$ \\
\hline
\end{tabular}

Sumber : Data diolah peneliti

Berdasarkan tabel 5.2 diatas dapat disimpulkan bahwa jawaban responden cenderung berada pada skala 2 yakni sebanyak 34\% responden menyatakan bahwa indikator dari Sistem Pengendalian Internal di Bank Daerah Lamongan masih belum berjalan dengan optimal, sehingga Pemerintah Kabupaten Lamongan terus melakukan pembenahan di sistem pengendalian internal karena sangat rawan akan adanya human error di pegawai Bank

2 Däerah 4amongan apabitatidek dilakukan pemantauan secara terus menerus.

\begin{tabular}{l|lll|l}
51 & 32 & 6 & 0 & Tabet 6.2 \\
Prosentase indikator Kualitas
\end{tabular}

\begin{tabular}{|c|c|c|c|c|c|c|c|}
\hline \multirow[b]{3}{*}{44} & & Serta & & Scev & nua & & \\
\hline & & & Keua & ggan & & & \\
\hline & 30 Indikator & $0_{1}$ & 2 & $0_{3}$ & 4 & 5 & $\begin{array}{l}\text { Respond } \\
\text { en }\end{array}$ \\
\hline 31 & Bqlevan6 & (26.6 & 40.6 & $50^{33}$ & $5 \mid 6$ & 0 & 50 \\
\hline 42 & $33_{\mathrm{dal}} \mathbf{5 . 6}$ & 0.90 .5 & $36.5^{1}$ & $\mathbf{0 O}_{28}$ & $7 ! 2$ & 0 & 50 \\
\hline & $\begin{array}{l}\text { Dapat } \\
\text { dibandingkan }\end{array}$ & 18 & 17 & 13 & 2 & 0 & 50 \\
\hline & $\begin{array}{l}\text { Dapat } \\
\text { dipahami }\end{array}$ & 11 & 23 & 14 & 2 & 0 & 50 \\
\hline & $\begin{array}{l}\text { Prosentase } \\
\text { (\%)Rata- } \\
\text { rata }\end{array}$ & 14.6 & 11.7 & 8.02 & 1.62 & 0.0 & 100 \\
\hline
\end{tabular}

Sumber : Data diolah peneliti

Berdasarkan tabel 6.2 diatas dapat disimpulkan bahwa jawaban responden cenderung berada pada skala 1 yakni sebanyak $14.6 \%$ responden menyatakan bahwa indikator dari Kualitas Keuangan di Bank Daerah Lamongan masih belum 
sesuai yang diharapkan oleh Pemerintah Kabupaten Lamongan sebagai pemegang kendali di Bank Daerah Lamongn. Kualitas laporan keuangan di Bank Daerah Lamongan terus menerus di pantau dan diperbaiki sistemnya secara bertahap agar menghasilkan suatu penajian laporan keuangan yg baik.

\section{Uji Kualitas Data}

Menurut Prof Jogiyanto H.M, Akt, Ph.D dan Willy Abdillah M.Sc, Partial Least Squares (PLS) merupakan analisis persamaan struktural berbasis varian yang secara simultan dapat melakukan pengujian model pengukuran sekaligus pengujian model struktural, metode analisis data dalam penelitian ini terbagi menjadi dua yaitu:

\section{Analisis deskriptif}

Statistik yang digunakan untuk menganalisa data dengan cara mendeskripsikan atau menggambarkan data yang telah terkumpul sebagaimana adanya tanpa bermaksud membuat kesimpulan yang berlaku untuk digeneralisasikan. Statistik deskriptif dalam penelitian ini antara lain: penyiapan data dalam bentuk tabel, gambar, perhitungan rerata skor, perhitungan prosentase, dan lain-lain (Sugiyono, 2013:206).

\section{Evaluasi Model}

Statistik inferensial adalah teknik statistik yang digunakan untuk menganalisis data sampel dan hasilnya diberlakukan untuk populasi (Sugiyono, 2013:207). Sesuai dengan hipotesis yang telah dirumuskan, maka dalam penelitian ini analisis data statistik inferensial diukur dengan menggunakan SmartPLS mulai dari pengukuran model (outer model), struktur model (inner model) dan pengujian hipotesis (Ghozali, 2014:32).

a. Model pengukuran atau outer model

Suatu konsep dan model penelitian tidak dapat diuji dalam suatu model prediksi hubungan relasional dan kausal jika belum melewati tahap purifikasi dalam model pengukuran (Hartono dan Abdillah, 2014:58). Model pengukuran digunakan untuk menguji validitas kontruk dan reliabilitas instrumen. Uji validitas dilakukan untuk mengukur kemampuan instrumen penelitian mengukur apa yang seharusnya diukur (Cooper dan Schindler, 2006 dalam Hartono dan Abdillah, 2014:58). Uji validitas kontruk dalam PLS dilaksanakan melalui uji Convergent validity, discriminant validity dan Average Variance Extracted (AVE).

Tabel 8.1

Outer Loadings (Factor Loading)

\begin{tabular}{|c|c|c|c|}
\hline & $\begin{array}{c}\text { KOMPETENSI } \\
\text { SDM (X1) }\end{array}$ & $\begin{array}{c}\text { KUALITAS } \\
\text { KEUAGAN } \\
(\mathrm{Y})\end{array}$ & S P I (X2) \\
\hline X1.1.1 & $\mathbf{0 . 4 8 8 3 4 2}$ & & \\
\hline X1.1.2 & 0.631498 & & \\
\hline X1.1.3 & $\mathbf{0 . 1 9 1 7 0 3}$ & & \\
\hline X1.2.1 & $\mathbf{0 . 4 1 9 1 6 9}$ & & \\
\hline X1.2.2 & 0.889368 & & \\
\hline X1.3.1 & $\mathbf{- 0 . 4 2 4 5 1 3}$ & & \\
\hline X1.3.2 & 0.773624 & & $\mathbf{0 . 2 9 6 3 0 5}$ \\
\hline X2.1.1 & & & 0.754772 \\
\hline X2.1.2 & & & $\mathbf{0 . 3 2 9 9 7 7}$ \\
\hline X2.2.1 & & & $\mathbf{0 . 2 3 4 0 4 1}$ \\
\hline X2.2.2 & & & $\mathbf{0 . 3 0 9 7 3 4}$ \\
\hline X2.3.1 & & & 0.852134 \\
\hline X2.3.2 & & & $\mathbf{- 0 . 4 3 2 0 8 2}$ \\
\hline X2.4.1 & & & $\mathbf{0 . 4 6 8 6 6 3}$ \\
\hline X2.4.2 & & & $\mathbf{0 . 0 6 4 2 1 2}$ \\
\hline X2.5.1 & & & $\mathbf{0 . 2 3 4 0 4 1}$ \\
\hline X2.5.2 & & & \\
\hline Y1.1 & & $\mathbf{0 . 4 7 0 9 9 1}$ & \\
\hline Y1.2 & & $\mathbf{0 . 2 1 3 8 2 6}$ & \\
\hline Y1.3 & & $\mathbf{0 . 7 0 1 7 3 7}$ & \\
\hline Y2.1 & & $\mathbf{- 0 . 7 1 9 7 9 5}$ & \\
\hline Y2.2 & & $\mathbf{- 0 . 4 0 5 8 1 4}$ & \\
\hline Y2.3 & & $\mathbf{- 0 . 0 8 5 7 7 3}$ & \\
\hline Y2.4 & & $\mathbf{- 0 . 2 5 9 5 8 5}$ & \\
\hline Y3.1 & & $\mathbf{- 0 . 1 8 7 0 4 8}$ & \\
\hline Y3.2 & & $\mathbf{- 0 . 3 2 5 0 6 6}$ & \\
\hline Sumber $:$ Data diolah oleh & & \\
\hline
\end{tabular}

Berdasarkan tabel outer loading di atas pada variable Kompetensi SDM (X1), indicator X1.1.1, X1.1.3, X1.2.1, X1.3.1, 
pada variable SPI (X2) indicator X2,1.1, $\mathrm{X} 2.2 .1, \mathrm{X} 2.2 .2, \mathrm{X} 2.3 .1, \mathrm{X} 2.4 .1, \mathrm{X} 2.4 .2$, $\mathrm{X} 2.5 .1, \mathrm{X} 2.5 .2$, dan pada variable kualitas Kualitas Keuangan (Y) Y1.1, Y1.2, Y2.1, Y2.2, Y2.3, Y2.4, Y3.1, Y3.2 memiliki nilai loading factor lebih kecil dari 0,5 , maka indiator tersebut dieliminasi dan tidak disertaan dalam proses pengolahan selanjutnya.

Convergent validity dari model pengukuran dengan model reflektif indikator dinilai berdasarkan korelasi antara item score / component score dengan construct score yang dihitung dengan PLS. Ukuran reflektif dikatakan tinggi jika berkorelasi lebih dari 0,70 dengan konstruk yang ingin diukur (Hartono dan Abdillah, 2014:61). Discriminant validity dari model pengukuran dengan reflektif indikator dinilai berdasarkan cross loading pengukuran dengan konstruk. Konstruk laten memprediksi ukuran pada blok yang lebih baik daripada ukuran blok lainnya apabila korelasi konstruk dengan item pengukuran lebih besar daripada korelasi dengan konstruk lainnya.

\section{Tabel 8.2}

Hasil pengolahan data setelah dilakukan eliminasi beberapa indicator sebagai berikut :

\begin{tabular}{|l|c|c|c|c|c|}
\hline & $\begin{array}{c}\text { Original } \\
\text { Sample } \\
(\mathrm{O})\end{array}$ & $\begin{array}{c}\text { Sample } \\
\text { Mean } \\
(\mathrm{M})\end{array}$ & $\begin{array}{c}\text { Standard } \\
\text { Deviation } \\
(\text { STDEV })\end{array}$ & $\begin{array}{c}\text { Standard } \\
\text { Error } \\
(\text { STERR })\end{array}$ & $\begin{array}{l}\text { T Statistics } \\
(\mid \mathrm{O} / \mathrm{STERR})\end{array}$ \\
\hline $\begin{array}{l}\text { X1.1.2<- } \\
\text { KOMPETENSI } \\
\text { SDM (X1) }\end{array}$ & $\mathbf{0 . 6 3 1 4 1 9}$ & 0.603860 & 0.183922 & 0.183922 & $\mathbf{3 . 4 3 3 0 7 5}$ \\
\hline $\begin{array}{l}\text { X1.2.2<- } \\
\text { KOMPETENSI } \\
\text { SDM (X1) }\end{array}$ & $\mathbf{0 . 9 1 6 2 4 6}$ & 0.922648 & 0.020726 & 0.020726 & $\mathbf{4 4 . 2 0 7 7 1 8}$ \\
\hline $\begin{array}{l}\text { X1.3.2<- } \\
\text { KOMPETENSI } \\
\text { SDM (X1) }\end{array}$ & $\mathbf{0 . 8 9 5 3 5 4}$ & 0.893405 & 0.043308 & 0.043308 & $\mathbf{2 0 . 6 7 3 9 8 7}$ \\
\hline $\begin{array}{l}\text { X2.1.2<-S P I } \\
\text { X2) }\end{array}$ & $\mathbf{0 . 8 8 7 4 4 5}$ & 0.876926 & 0.089776 & 0.089776 & $\mathbf{9 . 8 8 5 0 8 3}$ \\
\hline $\begin{array}{l}\text { X2.3.2<-S P I } \\
\text { (X2) }\end{array}$ & $\mathbf{0 . 9 3 4 6 9 1}$ & 0.942569 & 0.019020 & 0.019020 & $\mathbf{4 9 . 1 4 2 5 4 1}$ \\
\hline $\begin{array}{l}\text { Y1.3<- } \\
\text { KUALITAS } \\
\text { KEUANGAN } \\
(Y)\end{array}$ & $\mathbf{1 . 0 0 0 0 0 0}$ & 1.000000 & 0.000000 & & \\
\hline
\end{tabular}

Sumber: Data diolah oleh peneliti

Berdasarkan pada tabel outer loading di atas, Loading Factor ( muatan faktor), (misal untuk indicator X1.1.2 = $0,631, \mathrm{X} 1.2 .2=0,916$ dan seterusnya) $>$ 0,5 maka memenuhi validitas konvergen.
Hasil analisis pada table di atas menunjukkan bahwa seluruh indikator pada variabel penelitian yaitu variabel Kompetensi SDM, Satuan Pengawas Internal (SPI) dan Kualitas Keuangan memiliki loading factor $>0,5$, maka indicator tersebut memenuhi validitas konvergen.

Berdasarkan pada tabel outer loading di atas, Factor Loading Factor (muatan faktor) nilai T-Statistiknya (misal untuk X1.1.1=3,433, X1.2.2 = 44,207

$$
\text { Average Variance Extracted }
$$

(AVE) dapat digunakan untuk mengukur reliabilitas component score variabel laten dan hasilnya lebih konservatif dibandingkan dengan composite reliability. Direkomendasikan nilai $A V E$ harus lebih besar 0,50 (Fornnel dan Larcker, 1981 dalam Ghozali, 2014:40).

\section{Tabel 9}

Average variance extracted (AVE)

\begin{tabular}{|l|c|}
\hline & AVE \\
\hline $\begin{array}{l}\text { KOMPETENSI } \\
\text { SDM (X1) }\end{array}$ & 0.679952 \\
\hline $\begin{array}{l}\text { KUALITAS } \\
\text { KEUANGAN } \\
\text { (Y) }\end{array}$ & 1.000000 \\
\hline S P I (X2) & 0.830603 \\
\hline
\end{tabular}

penulis

Uji reliabilitas dalam PLS dapat menggunakan metode composite reliability dan cronbach's alpha (Hartono dan Abdillah, 2014:62). Composite reliability mengukur nilai sesungguhnya reliabilitas suatu kontruk dan lebih baik dalam mengestimasi konsistensi internal suatu kontruk (Salisbury et al, 2002 dalam Hartono dan Abdillah, 2014:62).

Rule of thumb nilai alpha atau composite reliability harus lebih besar dari 0,7, meskipun nilai 0,6 masih dapat diterima (Hair et al, 2006 Hartono dan Abdillah, 2014:62). 
Tabel 10

Composite Reliability

\begin{tabular}{|l|l|}
\hline & $\begin{array}{l}\text { Composite } \\
\text { Reliability }\end{array}$ \\
\hline $\begin{array}{l}\text { KOMPETENSI } \\
\text { SDM (X1) }\end{array}$ & 0.861421 \\
\hline $\begin{array}{l}\text { KUALITAS } \\
\text { KEUANGAN } \\
(Y)\end{array}$ & 1.000000 \\
\hline S P I (X2) & 0.907408 \\
\hline
\end{tabular}

Sumber : Data diolah oleh peneliti

b. Model struktural atau inner model

Inner model digunakan untuk uji kausalitas (pengujian hipotesis dengan model prediksi) serta menggambarkan hubungan antarvariabel laten berdasarkan pada teori substantif

$\frac{\text { Tabel 1 }}{\text { R-square }}$
\begin{tabular}{|l|l|}
\hline & $\begin{array}{l}\text { R } \\
\text { Square }\end{array}$ \\
\hline $\begin{array}{l}\text { KOMPETENSI } \\
\text { SDM (X1) }\end{array}$ & \\
\hline $\begin{array}{l}\text { KUALITAS } \\
\text { KEUANGAN } \\
(Y)\end{array}$ & 0.201610 \\
\hline S P I (X2) & 0.790112 \\
\hline
\end{tabular}
peneliti

Sumber : Data diolah oleh

Nilai $R^{2}=1-(1-0,2016)(1-0,79011)=$ 0,8134, hal ini dapat diinterpretasikan bahwa model sangat Baik dan mampu menjelaskan fenomena/masalah Kualitas Keuangan sebesar 81,34 \%, sedangkan sisanya $(18,66 \%)$ dijelaskan oleh variabel lain [selain Kompetensi SDM, Satuan Pengawas Internal (SPI)] yang belum masuk ke dalam model dan error

\section{Pengujian hipotesis}

Hartono dan Abdillah (2009) menjelaskan bahwa ukuran signifikansi keterdukungan hipotesis dapat digunakan perbandingan nilai $t$-table dan $t$-statistic. . Dalam penelitian ini untuk tingkat keyakinan 90 persen $(\alpha=10 \%)$ maka nilai t-table untuk hipotesis satu ekor (onetailed) adalah $>1,680$.
Tabel 12

Path Coefficients (Mean, STDEV, TValues)

\begin{tabular}{|c|c|c|c|c|c|}
\hline & $\begin{array}{c}\text { Orig } \\
\text { inal } \\
\text { Sam } \\
\text { ple } \\
(0)\end{array}$ & $\begin{array}{c}\text { Sample } \\
\text { Mean } \\
\text { (M) }\end{array}$ & $\begin{array}{l}\text { Standard } \\
\text { Deviation } \\
\text { (STDEV) }\end{array}$ & $\begin{array}{l}\text { Standard } \\
\text { Error } \\
\text { (STERR) }\end{array}$ & $\begin{array}{c}\mathbf{T} \\
\text { Statistics } \\
(\mid \mathbf{O} / \mathbf{S T E R} \\
\mathbf{R} \mid)\end{array}$ \\
\hline $\begin{array}{l}\text { KOMPET } \\
\text { ENSI SDM } \\
(\mathrm{X} 1)-> \\
\text { KUALITA } \\
\text { S } \\
\text { KEUANG } \\
\text { AN (Y) }\end{array}$ & $\begin{array}{c}0.34 \\
7140\end{array}$ & 0.329390 & 0.486545 & 0.486545 & 0.713479 \\
\hline $\begin{array}{l}\text { KOMPET } \\
\text { ENSI SDM } \\
(\mathrm{X} 1)->\text { S P } \\
\mathrm{I}(\mathrm{X} 2)\end{array}$ & $\begin{array}{l}0.88 \\
8882\end{array}$ & 0.898520 & 0.024705 & 0.024705 & 35.980014 \\
\hline $\begin{array}{l}\text { S P I (X2) - } \\
> \\
\text { KUALITA } \\
\text { S } \\
\text { KEUANG } \\
\text { AN (Y) }\end{array}$ & $\begin{array}{l}0.11 \\
1334\end{array}$ & 0.113892 & 0.476971 & 0.476971 & 0.233419 \\
\hline
\end{tabular}

Berdasarkan tabel diatas dapat disimpulkan bahwa antara variabel Kompetensi dan Sistem pengendalian internal mengalami pengaruh yang berbeda terhadap kualitas keuangan, sebagai berikut :

1. Kompetensi SDM tidak berpengaruh secara Non Signifikan terhadap Kualitas Keuangan dengan koefisien path sebesar 0,3471, dimana nilai $\mathrm{T}$ Statistic $=0,713$ lebih kecil dari nilai $Z \alpha=0,10(10 \%)=1,645$

2. Kompetensi SDM berpengaruh Positif Signifikan terhadap SPI (Y) dengan koefisien path sebesar 0,888 , dimana nilai $\mathrm{T}$-Statistic $=$ 35,980 lebih besar dari nilai $\mathrm{Z} \alpha=$ $0,10(10 \%)=1,645$,

3. SPI tidak berpengaruh secara Non Signifikan terhadap Kualitas Keuangan dengan koefisien path sebesar 0,111, dimana nilai $\mathrm{T}$ Statistic $=0,233$ lebih kecil dari nilai $Z \alpha=0,10(10 \%)=1,64$

\section{PEMBAHASAN}

\section{Pengaruh Kompetensi SDM terhadap Kualitas Keuangan}

Berdasarkan hasil pengujian hipotesis yang telah di uji menunjukkan bahwa Kompetensi SDM tidak berpengaruh secara Non Signifikan terhadap Kualitas Keuangan. Artinya kuat atau lemahnya Kompetensi SDM tidak 
memberikan pengaruh terhadap Kualitas Keuangan Bank Daerah Lamongan.

2. Pengaruh Sistem Pengendalian Keuangan terhadap Kualitas Keuangan

Berdasarkan hasil pengujian hipotesis yang telah di uji menunjukkan bahwa Sistem Pengendalian Internal (SPI) tidak berpengaruh secara Non Signifikan terhadap Kualitas Keuangan. Artinya Kuat atau lemahnya Sistem Pengendalian Internal terhadap Kualitas keuangan Bank Daerah Lamongan

3. Pengaruh Kompetensi SDM melalui Sistem Pengendalian Internal terhadap Kualitas Keuangan

Berdasarkan hasil pengujian hipotesis yang telah di uji menunjukkan bahwa Kompetensi SDM melalui Sistem Pengendalian Internal (SPI) berpengaruh Signifikan terhadap Kualitas Keuangan. Artinya Kompetensi SDM mempunyai pengaruh kuat melalui SPI terhadap Kualitas keuangan Bank Daerah Lamongan

\section{Kesimpulan}

a. Kompetensi SDM tidak berpengaruh secara Non Signifikan terhadap Kualitas Laporan Keuangan PD Bank Daerah Lamongan. Semakin tinggi Kompetensi SDM yang dimiliki PD Bank Daerah Lamongan, maka Kualitas Keuangan yang dihasilkan PD Bank Daerah Lamongan cenderung semakin baik.

b. Kompetensi SDM melalui Sistem Pengendalian Internal (SPI). berpengaruh Signifikan terhadap Kualitas Laporan Keuangan PD Bank Daerah Lamongan Semakin tinggi kompetensi yang dimiliki PD Bank Daerah Lamongan melalui peningkatan penerapan SPI, berdampak pada meningkatnya Kualitas Laporan
Keuangan PD Bank Daerah Lamongan.

\section{Saran}

1. Kompetensi SDM merupakan suatu variabel penentu dalam menilai kualitas keuangan PD Bank Daerah Lamongan. Suatu pengelolaan Kompetensi SDM yang tinggi melalui Sistem Pengendalian Internal yang baik dan optimal, secara otomatis akan meningkatkan Kualitas Keuangan PD Bank Daerah Lamongan.

2. Pemahaman dan penerapan SDM melalui SPI perlu terus ditingkatkan agar menghasilkan suatu Laporan Keuangan yang berkualitas. PD Bank Daerah Lamongan dalam meningkatkan suatu kualitas keuangan, maka PD Bank Daerah Lamongan secara rutin mengadakan Pelatihan penyusunan Laporan Keuangan dan sosialaisasi atas peraturan yang berkaitan keuangan mengingat PD Bank Daerah Lamongan memiliki pegawai yang berlatar belakang pendidikan yang beragam.

\section{DAFTAR PUSTAKA}

Arikunto, Suharsimi. 1993. Manajemen Pengajaran : Secara Manusiawi. Jakarta:Rineke

Cipta. 1998. Prosedur Penelitian Suatu Pendekatan Praktek. Jakarta : Rineke Cipta. 2002. Prosedur Penelitian Suatu Pendekatan Praktek. Jakarta : PT. RinekaCipta.

Moekijat. 1989. Administrasi Perkantoran. Bandung : Mandar Maju

Nitisemito, Alex S. 1983. Manajemen Personalia, Cetakan ke III, Penerbit : Ghalia Indonesia.

Sutrisno, Hadi. 1993, Statistik 2, Yogyakarta, Penerbit Andi, Yogyakarta

Ajija, Schochrul Rohmatul, dkk. 2011. "Caa Cerdas Menguasai Eviews". Jakarta. Salemba Empat.

Alhadar, Mohamad Audi. 2013. "FaktorFaktor yang mempengaruhi 
karir". Makassar: Universitas Hasanudin.

Bungin, Burhan. 2005. "Metodologi Penelitian Kuantitatif Edisi Pertama". Jakarta. Pranada Media Group.

Jurnal Media Wahana Ekonomika, Vol. 8, No. 3, Oktober 2011:1-15

Sari Simatupang, Mei. 2017. Pengaruh Sistem Pengendalian Intern Pemerintah, Sistem Akuntansi Keuangan Daerah Dan Kompetensi Sumber Daya Manusia Terhadap Efektivitas Pengelolaan Keuangan Daerah (Studi Pada Satuan Kerja Perangkat Daerah Kota Padangsidimpuan). Pekanbaru : Fakultas Ekonomi Riau University.

Puspandoyo, Teguh. 2014. Analisis Hubungan Antara Enterprise Resource Planning Dengan Efektivitas Pengendalian Internal Pada Sektor Perbankan. Program Studi Magister Akuntansi Fakultas Ekonomi Dan Bisnis Universitas Sebelas Maret.

Surat Edaran Bank Indonesia nomor 5/22/DPNP Tentang Pedoman Standar Sistem Pengendalian Intern bagi Bank Umum

Republik Indonesia.2010. Peraturan Pemerintah Nomor 71 tahun $2010 \quad$ Tentang Standar Akuntansi Pemerintahan.

Sugiyono. 2013. Metode Penelitian Kuantitatif Kualitatif dan $R \&$. Bandung: Alfabeta.

Sugiyono. 2016. Statistika Untuk Penelitian. Bandung: Alfabeta

Prof Jogiyanto H.M, Akt, Ph.D dan Willy Abdillah M.S. 2016. Konsep dan Aplikasi PLS (Partial Least Squares). BPFE: Yogyakarta

Shahwan, Yousef 2008 Qualitative Characteristics of Financial Reporting: A Historical Perspective. Journal of Applied Accounting Research. 9 (3), pp. 192-202

Jurnal Penelitian IImu Manajemen
Arens, A.A, Elder R.J, dan Beasley, M.S. 2014. Auditing dan Jasa Assurance. Edisi Kelima Belas Jilid 1. Alih Bahasa: Herman Wibowo dan Tim Perti. 2014 Jakarta : Erlangga

Syarifudin, A. 2014. Pengaruh Kompetensi SDM dan Peran Audit Intern terhadap Kualitas Laporan Keuangan Pemerintah Daerah dengan Variabel Intervening Sistem Pengendalian Internal Pemerintah (Studi Empiris pada Pemkab Kebumen). Jurnal Fokus Bisnis.

JOM Fekon. (Februari) 2017. Vol.4 No.1 Jurnal Ilmu dan Riset Akuntansi. Maret 201. Volume 6 Nomor 3

Furqon. 2009. Statistika Terapan untuk Penelitian. Bandung : ALFABETA 